\title{
Compositional homogeneity of textured KNN-based ceramics
}

\author{
Rafiq, M.A. , Pinho, R. , Costa, M.E.* Vilarinho, P.M.*
}

*Department of Materials and Ceramic Engineering, Centre for Research in Ceramics and Composite Materials, CICECO, University of Aveiro, 3810-193 Aveiro, Portugal.

Email : asifrafiq@ua.pt

Smart materials like piezoelectrics and ferroelectrics play a crucial role in applications such as sensors and actuators, radio-frequency switching, drug delivery, chemicals detection, and power generation and storage. $\mathrm{Pb}\left(\mathrm{Zr}_{\mathrm{x}}, \mathrm{Ti}_{1-\mathrm{x}}\right) \mathrm{O}_{3}(\mathrm{PZT})$, close to the morphotropic phase boundary (MPB) with a composition of about $\mathrm{x}=$ 0.5 is currently the most widely used material for electromechanical applications [1]. Even though, with suitable properties of PZT, there is a need to search for alternative lead free material because of the unfriendly behaviour of $\mathrm{PbO}$ towards environment $[1,2]$. In this regard $\mathrm{K}_{0.5} \mathrm{Na}_{0.5} \mathrm{NbO}_{3}(\mathrm{KNN})$ attracted special attention to replace (PZT) by the report of comparable electromechanical response of $\mathrm{Li}, \mathrm{Ta}$ and $\mathrm{Sb}$ doped KNN based ceramics [1]. Although pure KNN has inferior electromechanical properties compared to PZT, efforts are on going to tailor and improve its piezoelectric coefficients by doping and texturing $[2,3]$.

Templated (TGG), in which preferentially oriented growth of large, template grains were observed by consuming the matrix grains during the densification process is one of promising route to control the texture / microstructure. TGG used in this work where $\left(\mathrm{K}_{0.49} \mathrm{Na}_{0.49}\right) \mathrm{Li}_{0.2} \mathrm{O}_{3}$ matrix having average particle size of $\sim 1 \mu \mathrm{m}$ and (001)-oriented $\mathrm{K}_{0.50} \mathrm{Nb}_{0.50} \mathrm{NbO}_{3}$ single crystal template passing through sieve of $45 \mu \mathrm{m}$, previously grown by high temperature self flux grown method was used [1]. $\left(\mathrm{K}_{0.49} \mathrm{Na}_{0.49}\right) \mathrm{Li}_{0.2} \mathrm{O}_{3}$ matrix along with $10 \mathrm{wt} \%$ of single crystal templates having perovskite $\left(\mathrm{ABO}_{3}\right)$ structure was synthesized by a conventional mixed oxide method. Sintering was carried out at $1100{ }^{\circ} \mathrm{C}$ for the various sintering times between $2 \mathrm{~h}$ to $24 \mathrm{~h}$. The main objective of this work is to produce textured KNN based mono-phasic ceramics with compositional homogeneity. Compositional inhomogeneities normally exist in muticomponent systems. Mono-phasic and compositionally homogeneous ceramics are very important in controlling and understanding the properties [4].

Electromechanical properties are very much dependent on the crystalline phase content, crystallographic orientation, microstructure, interfaces and domain configurations. X-ray diffraction analysis showed monophasic ceramics. The texture fraction of the (001) planes was estimated from the XRD patterns using the Lotgering method. The Lotgering factor (f) is defined as the fraction of the area textured with the crystallographic plane of interest using $f=\frac{P_{00 l}-P_{0}}{1-P_{0}}$. Lotgering factor (f) of $40 \%$ was obtained for ceramic sintered for $24 \mathrm{~h}$ as shown in figure 1. Figure 2 shows the SEM, energy dispersive spectra (EDS) and elemental mapping of Li doped KNN ceramics sintered for 24 hours. An EDS spectrum reveals only the $\mathrm{K}, \mathrm{Na}, \mathrm{Nb}$ and $\mathrm{O}$ on the surface of the samples. In addition, elemental mapping for $\mathrm{K}$, $\mathrm{Na}, \mathrm{Nb}$ and $\mathrm{O}$ was also performed on the surface of the ceramics. Figure 2 (c-f), confirming the distribution is very uniform ascertaining the good chemical quality of the textured sample sintered for 24 h. In conclusion, XRD and SEM with the help of EDS confirmed that we have successfully prepared mono-phasic and compositionally homogeneous textured ceramics expected to show better performance.

Muhammad Asif Rafiq acknowledge PEst-C/CTM/LA0011/2011.

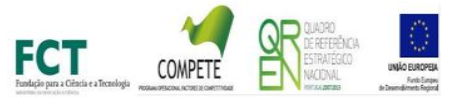


[1] Saito Y. et al., Nature, 432, 84-87, 2004.

[2] Wang K. et al., Adv. Funct. Mater., 20, 1924-29, 2010.

[3] Rafiq M.A. et al., Microscopy and Microanalysis, 19, 99-100, 2013.

[4] Wang Y. et al., J. Am. Ceram. Soc., 90, 3485-3489, 2007.

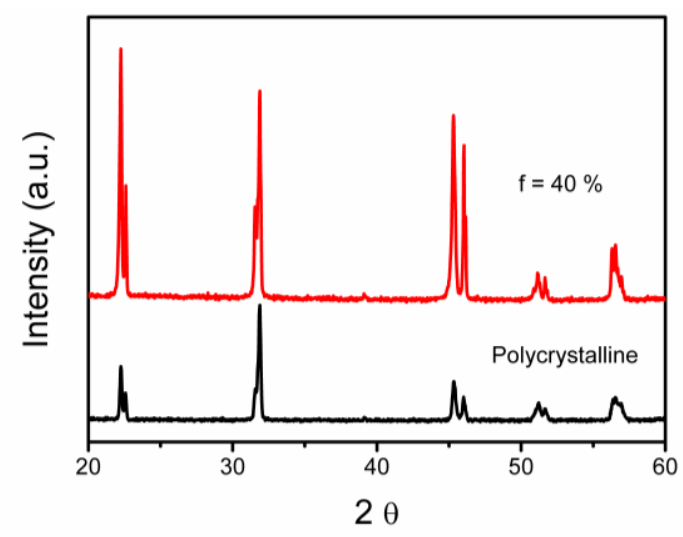

Fig. 1 - XRD spectra of polycrystalline and textured $\left(\mathrm{K}_{0.49} \mathrm{Na}_{0.49}\right) \mathrm{Li}_{0.2} \mathrm{O}_{3}$ ceramics.
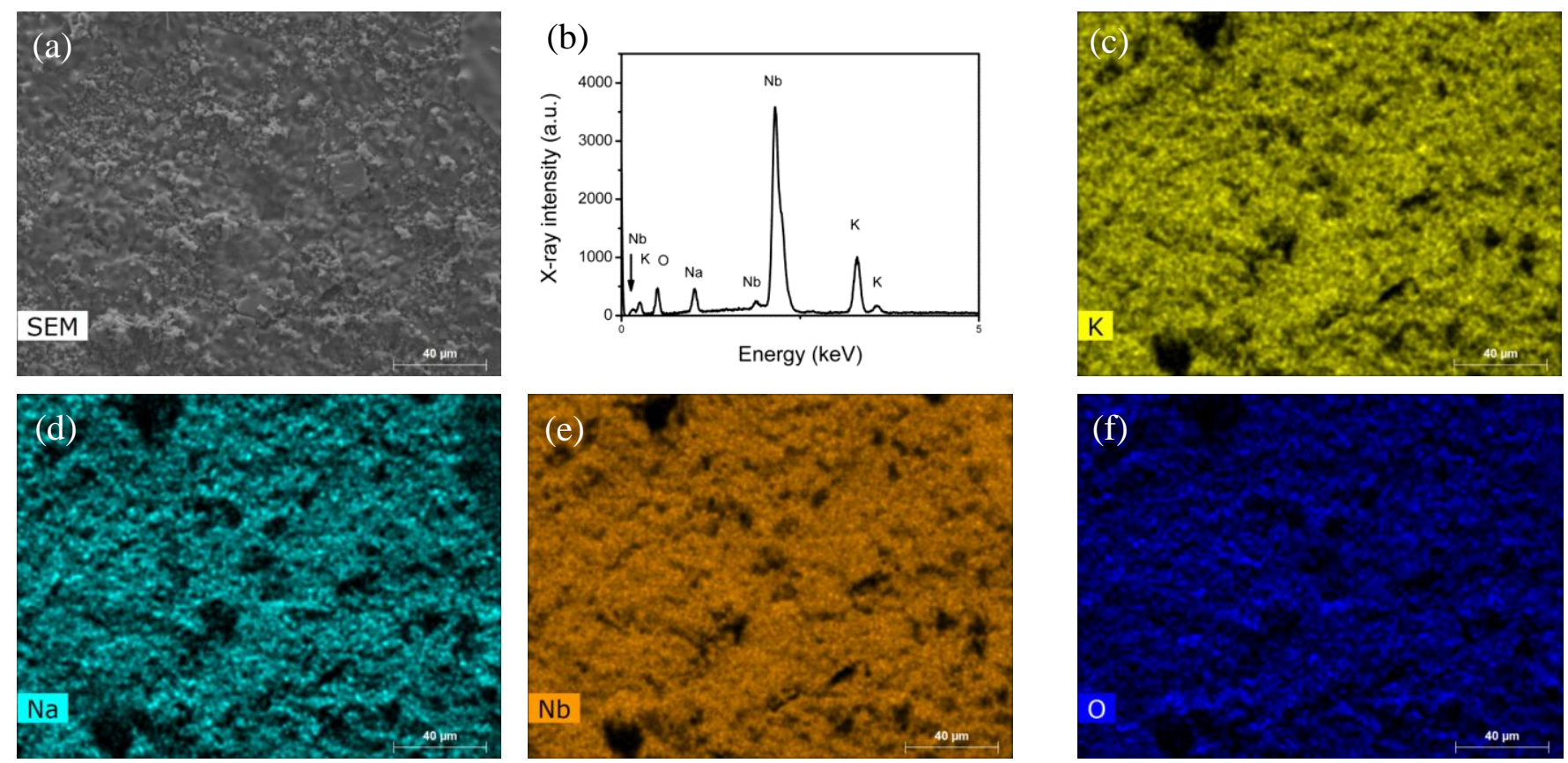

Figure 2. SEM elemental mapping of $\left(\mathrm{K}_{0.49} \mathrm{Na}_{0.49}\right) \mathrm{Li}_{0.2} \mathrm{O}_{3}$ textured ceramic sintered for 24h: (a) SEM image, (b) EDS spectra, where (c), (d), (e) and (f) represent potassium, sodium, niobium, and oxygen distributions, respectively. 